\title{
DEVELOPMENT OF AN INSTRUMENT FOR AFFECTIVE RISK IN BUSINESS-TO- CONSUMER E-COMMERCE
}

\author{
Wei Sha, Pittsburg State University, wsha@pittstate.edu
}

\begin{abstract}
The focus of this research is to develop an instrument for affective risk and validates the instrument's validities in B2C e-commerce context. This research based its conceptualization of affective risk on the risk-as-feelings theory, which emphasizes that people's anticipatory visceral affect will influence their subsequent behavior over and above the influence of their cognitive evaluations. Data were collected through two survey studies, and the findings found that the instrument is effective in measuring affective risk. The impact of the affective risk on behavioral intentions is also supported by the findings.
\end{abstract}

Keywords: Risk-as-Feeling theory, Cognitive risk, Affective risk, Feelings, B2C e-commerce

\section{INTRODUCTION}

Although there is tremendous growth in business-to-consumer (B2C) e-commerce, relatively unknown vendors could still face stiff challenges. Some of the challenges might come from customers who might believe that it is too risky to purchase online from unfamiliar vendors. Examining the mechanism of these concerns became an important research stream in the Information Systems (IS) literature (Jarvenpaa, et al., 2000, McKnight, et al., 2002a, b, Featherman \& Pavlou, 2003, Fortis \& Rita, 2016, Yang, et al, 2015; Yen, 2015), etc. Most studies examined risk as an individual's cognitive beliefs about the probabilities of negative outcomes in B2C e-commerce. However, consumers' risk concerns are not limited to just cognitive in nature. These concerns can also generate emotional responses, i.e. negative feelings, which might also play vital roles in determining behavioral intentions. The theory of affect emphasizes the importance of feelings and proposes that affective responses could have significant or even primary influence on behavioral intentions (Crites, Fabrigar \& Petty, 1994; Loewenstein, Weber, Hsee \& Welch, 2001). Some IS research indicated that people's risk concerns could have both cognitive and affective components (Bhattacherjee, 2002; Featherman \& Pavlou, 2003; Gefen et al., 2003). These research found that uncertain circumstances could cause feelings of conflict, anxiety or discomfort. This research labels the affective components of risk concerns as affective risk. In general, these negative feelings did not receive enough attention as much as their cognitive counterparts in IS research, and a validated measurement instrument is also lacking. The current study aims to fill the gap by explores the origin and nature of affective risk feelings and attempts to develop a measurement instrument for affective risk. The results from this examination and validation would provide a more complete picture about consumer behaviors in $\mathrm{B} 2 \mathrm{C}$ e-commerce.

The rest of the paper is organized as follows: first, the construct of affective risk is introduced based on the risk-asfeeling theory; second, affective risk is compared with other constructs, such as cognitive risk and computer anxiety. The boundaries of affective risk is further defined; third, results from the analysis of data gathered through two survey studies are presented; and last, discussion, contributions and limitations of the research are presented.

\section{THE RISK AS FEELING THEORY}

Affective risk is defined as a person's anticipatory negative feelings, such as worry, fear or anxiety about loss, vulnerability or threat in an uncertain environment. People may experience these feelings when they face difficult choices that could have serious consequences in an uncertain or risky environment. These feelings, in turn could direct people to an action different from the one which would be otherwise selected based on their cognitive and rational evaluations of the situation. In $\mathrm{B} 2 \mathrm{C}$ ecommerce, it is risky for consumers to purchase online, because of 
their unfamiliarity with the legitimacy, privacy and security of unknown web vendors (Torkzadeh and Dhillon, 2002). As a result, people may experience negative feelings about the web vendors, which may prompt them to abandon their shopping cart or to browse a competitor's website for more information. The theoretical sources of affective risk can be traced to the theory of affect which emphasizes the importance of affect in human behaviors. Affect, a categorical construct (Bagozzi, Gopinath, and Nyer, 1999), is one of three components of people's attitudinal responses (Crites, Fabrigar and Petty, 1994), i.e. affect, cognition, and conation, which are antecedents of behavioral intentions and actual behaviors. This tripartite separation of people's attitudinal responses argues that people's behavior is determined not only by their cognitive evaluations of the situation but also by their current feelings. As for the negative feelings, their impact can be best explained by by the risk-as-feeling theory (Loewenstein, et al., 2001).

The risk-as-feelings theory proposes that people's anticipatory negative emotions (i.e. worry, fear, dread, or anxiety, etc.), generated as the results of encountering a risky or uncertain situation, may have direct influence on people's responses beyond that of their cognitive evaluations. The theory proposes that people's behavioral choice is a function of both their cognitive evaluations of the uncertain or risky situation and their emotional reactions to the situation. Both cognitive risk and affective risk share the same set of antecedents, i.e. anticipated outcomes and their associated probabilities. Affective risk and cognitive risk could also have mutual influence on each other. More importantly, the risk-as-feeling theory particularly proposes that behavioral response can be triggered by affective risk alone. This unique effect of affective risk can be attributed to the separate set of antecedents for affective risk, such as vividness, time immediacy and background mood. These unique antecedents do not influence the anticipated outcomes or probabilities, and therefore have no impact on cognitive risk. Therefore, it is possible that people's behaviors would be influenced by their affective risk alone without any involvement or realization of their cognitive evaluations of the risky situation. The essence of risk-as-feeling theory is shown in Figure 1.

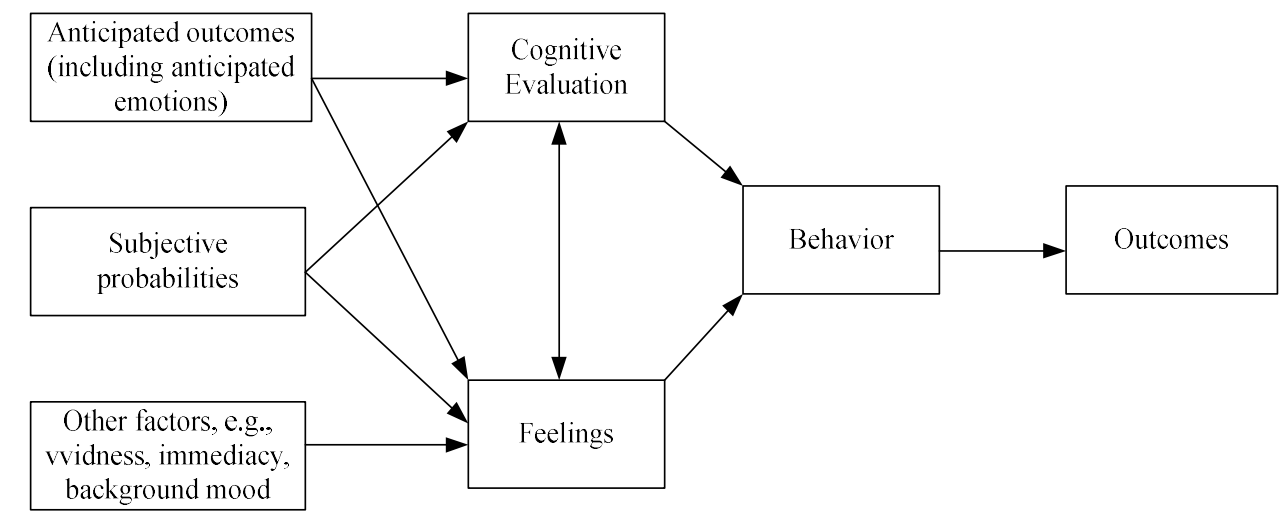

Figure 1. the Risk-As-Feeling Theory

\section{THE BOUNDARIES OF AFFECTIVE RISK}

First, affective risk and cognitive risk attempt to capture different aspects of human responses to a threat or in an uncertain environment. Affective risk aims to capture a person's emotional feelings while cognitive risk aims to capture the cognitive beliefs or calculations in the uncertain environment. Cognitive risk beliefs are a person's salient assessment of the severity and likelihood of negative outcomes and may require a certain amount of brain processing of the threat or uncertainty. Affective risk feelings do not require prolonged brain processing which 


\section{Issues in Information Systems \\ Volume 19, Issue 3, pp. 11-21, 2018}

indicates less calculation is involved, and therefore, could be triggered immediately. These feelings are a person's feelings of worry, fear or anxiety in anticipation of the negative outcomes of the person's behavior.

Different brain functions in reaction to threats or uncertainty are responsible for affective risk feelings and cognitive risk beliefs (LeDoux, 1996). When the sensory thalamus receives threat signals, it could either send the signal directly to the amygdale or send the signals to the cortical system for processing and then the results are sent to the amygdale, without any mediation of the cortex. The instructions sent by the amygdale direct the human body to produce powerful emotions, which in turn direct motor response. For example, after subjects received intravenous injections of procaine, they reported powerful emotions, including panic sensations, although there was no apparent cognitive processing (Servan-Schreiber and Perlstein, 1998). When the amygdale is stimulated electronically, people report foreboding, another powerful feeling (Panksepp, 1985, 1998). The ventromedial prefrontal cortex can also play a role in affective risk generation. A severely damaged ventromedial prefrontal cortex could cause the inability to generate necessary affective responses. As the result, an individual tends to consistently make very poor decisions and judgments even when the individual's cognition skills are intact. These negative emotions can also be called anticipatory emotions (Loewenstein, Weber, Hsee and Welch, 2001), which can be elicited, retrieved and processed faster than cognitive beliefs (Murphy and Zajonc, 1993). This unique nature of anticipatory emotion causes people to sometimes react emotionally to a stimulus before they even realize what the stimulus is (Zajonc, 1980). Subsequently, affective risk may have dominant influence over people's actions in risky situations. For example, people often react negatively to sudden sound before they find the source of the sound. In social contexts, people often like or dislike a person or objects without even remembering any particular reasons, which would require extensive cognitive processing (Bargh, 1984).

Second, affective risk is different from computer anxiety. Computer anxiety is a construct about the negative emotions while using a computer (Compeau, Higgins and Huff, 1999). Specifically, computer anxiety is defined as "an individual's apprehension, or even fear, when she/he is faced with the possibility of using computers" (Venkatesh, 2000, p. 349). Affective risk, on the other hand, is referring to the general influence of negative emotions on behavior choices in a much broader context. Additionally, the examination of the influence of computer anxiety on dependent constructs is usually done through cognitive theoretical framework lenses. As a result, the role of computer anxiety in the nomological network is secondary, and cognitive processes could mediate computer anxiety's impact on dependent variables. Affective risk, as discussed above, could have primary and direct influence on dependent variables. Furthermore, the conceptualization and measurement of computer anxiety do not relate specifically to the negative outcomes of the potential behaviors. This is different from the conceptualization and measurement of affective risk.

Third, the conceptualization of affective risk is different from the negative emotions measured in consumption literature. The measurement items for the negative emotions in the marketing literature are usually parts of an overall measurement scale for consumption emotions, such as the consumption emotion set (Richins, 1997). These measurement scales do not focus specifically on the negative emotions associated with potential risky outcomes of a behavior choice.

Feelings of risk could influence behavioral intentions in B2C. Online shopping poses a special challenge to customers. It is likely that they may visit unknown web vendors' websites through embedded commercial hyperlinks, online merchant listings, or lists of vendors as the result of an online price comparison. Since their experiences with these vendors are limited, consumers may worry about, fear or dread the negative consequences of potential behavioral choices, such as monetary loss, privacy invasion, or emotional drain. These affective risk feelings would prevent them from pursuing further business transactions with the unfamiliar vendors. In consumption context, consumers facing uncertainty may feel anxiety, fear or dread. These feelings could make consumers reluctant to be cooperative. The influences of these negative feelings could be especially more salient to consumers when they engage in online shopping. Therefore, based on the risk-as-feeling theory and evidence from supporting literature, this research proposes that affective risk will be negatively correlated with behavioral intentions in a B2C ecommerce context.

To summarize, based on the above theoretical justification about affective risk, this study proposes the following hypotheses about affective risk and develops an instrument for this construct: 
Hypothesis $1(\mathrm{H} 1)$ : Affective risk will demonstrate discriminant validity with cognitive risk.

Hypothesis $2(\mathrm{H} 2)$ : Cognitive risk would have a significant influence on affective risk.

Hypothesis 3 (H3): affective risk will have negative influence on behavioral intentions above and beyond cognitive risk.

\section{METHODOLOGY}

New scales were developed for affective risk because of a lack of suitable instruments. The development of the scales followed the three step approach proposed by Clark and Watson (1995): conceptualization of the construct and generation of an initial item pool, item selection and psychometric evaluation, and the testing of external validity. The items were narrowed down in the study I, and the measurement items were further refined and their validities were examined in Study II. Instruments for cognitive risk and behavioral intentions were adopted and modified from existing studies.

The items were selected from a pool of items which were generated either based on their definitions or from existing instruments for related constructs. Domain experts examined the item wordings to make sure the items were written properly so that participants could understand the items correctly while the intended domain areas of the items were still intact. The items for affective risk are listed in Table 1.

Table 1. Affective Risk Items

\begin{tabular}{|l|l|}
\hline & \multicolumn{1}{|c|}{ Items } \\
\hline 1 & I worry about this web vendor's customer service \\
\hline 2 & I fear possible monetary loss if I purchase from this web vendor \\
\hline 3 & I worry about this web vendor being a fly-by-night operation \\
\hline 4 & I feel tense when I am going to purchase from this web vendor \\
\hline 5 & I am concerned about possible privacy violations from this web vendor \\
\hline 6 & I worry about my order if I purchase from this web vendor \\
\hline 7 & I feel uneasy about the quality of the product offered by this web vendor \\
\hline 8 & I worry about the product information provided by this web vendor \\
\hline
\end{tabular}

Established scales were used to measure cognitive risk and behavioral intentions. All the items were adapted to reflect the online shopping context. The following Table 2 contains measurement items for cognitive risk and behavioral intentions. The measurement items for cognitive risk were adapted from existing instruments (Featherman and Pavlou, 2003; Jarvenpaa, et al. 2000; McKnight, et al., 2002b). Cognitive risk is a multidimensional construct which may contain consumers' salient beliefs about various threats of a potential choice, such as product malfunctions, identity theft or financial losses (Featherman and Pavlou, 2003). Therefore, the selected cognitive risk items were intended to capture participants' perception about the degree to which it was safe to complete a transaction in terms of product performance, order fulfillment, or personal information and financial information security. Six items adopted from McKnight's et al. (2002 a, b) instrument for trusting intentions were used to measure participants' behavioral intentions. More specifically, two items were used to measure participants' willingness to depend, i.e. the extent to which participants were willing to rely on a web vendor, three items were used to measure participants' intentions to adopt the web vendor's services including purchase intentions, and one item was used to measure participants' willingness to provide personal information to the web vendor. 


\section{Issues in Information Systems \\ Volume 19, Issue 3, pp. 11-21, 2018}

Table 2. Cognitive Risk and Behavioral Intention Items

\begin{tabular}{|l|l|}
\hline \multicolumn{1}{|c|}{ Constructs } & \multicolumn{1}{c|}{ Measurement Items } \\
\hline Cognitive Risk & Entering credit card information on this vendor's website is unsafe. \\
\hline & This web vendor might ship me products that do not function properly. \\
\hline & I might receive wrong products from this web vendor. \\
\hline & My personal information could be sold to other companies. \\
& $\begin{array}{l}\text { The chances are great that purchasing from this web vendor will result in } \\
\text { negative consequences. }\end{array}$ \\
\hline & The web vendor may alter the facts in order to get what it needs. \\
\hline & It is risky to give my personal information to this web vendor. \\
\hline & My credit card information might not be secure with this web vendor. \\
\hline & I might not receive my ordered product. \\
\hline & Overall, purchasing from this website is very risky. \\
\hline & $\begin{array}{l}\text { I can always rely on this web store to meet my shopping needs. } \\
\text { Intentions }\end{array}$ \\
\hline & I trust this web store completely. \\
\hline & I would use my credit card to purchase from this web store. \\
\hline & $\begin{array}{l}\text { I am very likely to provide the web store with the information it needs to } \\
\text { better serve my needs. }\end{array}$ \\
\hline & I intend to use this web vendor's service. \\
\hline & I intend to purchase from this web vendor. \\
\hline
\end{tabular}

\section{Study I}

The purpose of study I was to develop appropriate measurement scales for affective risk. 219 undergraduate students from a Midwestern university participated in this study. Participants were asked to shop for a gift online. They were instructed to visit a web store of their choice to select an interested item. Participants were then asked to answer questions about their feelings or concerns regarding their online shopping experience. These participants have a mean age of 22 , and $58 \%$ of them are male. Their average online experience is 7.5 years. Their average purchase is about 10 times per person. Additionally, the group purchases from well known websites, such as Ebay.com, Amazon.com, Best Buy and other apparel websites. These facts reflect the fact that the participants belong to the same demographic group. This profile fits the fact that the data were collected from undergraduate students.

\section{Results}

Confirmatory factor analysis with AMOS 5.0, a structural equation modeling (SEM) software package, was used to examine the measurement model and establish each construct's convergent validity, discriminant validity and predictive validity. Items which did not contribute to the explanation of the variance of the intended constructs were trimmed to provide better explanation power and improved fit indices.

The first indication of convergent and discriminant validity is the fit of the proposed model to the data. Several fit indices were used to assess the goodness of fit, such as the discrepancy ratio $\left(\chi^{2} / \mathrm{df} ; \mathrm{df}=\right.$ degrees of freedom), the adjusted goodness-of-fit (AGFI), the Tucker-Lewis index (TLI), the comparative fit index (CFI), the normative fit index (NFI), and the root mean square error of approximation (RMSEA). Table 3 lists the values for these fit indices along with the threshold values for an acceptable fit. The fit values all exceed the threshold values for better fit. This comparison demonstrates satisfactory levels of fit for the measurement model.

Table 3. Model Fit Indices

\begin{tabular}{|l|l|l|l|l|l|l|}
\hline \multicolumn{1}{|c|}{ Fit indices } & \multicolumn{1}{c|}{ Discrepancy ratio } & \multicolumn{1}{c|}{ AGFI } & \multicolumn{1}{c|}{ TLI } & \multicolumn{1}{c|}{ CFI } & \multicolumn{1}{c|}{ NFI } & RMSEA \\
\hline Threshold & $<2.0$ & $>.80$ & $>.90$ & $>.90$ & $>.90$ & $<.08$ \\
\hline Values & 1.525 & .89 & .97 & .98 & .94 & .049 \\
\hline
\end{tabular}




\section{Issues in Information Systems \\ Volume 19, Issue 3, pp. 11-21, 2018}

To establish convergent validity, the next step is to examine individual items' factor loadings for their intended latent constructs. The factor loading should be greater than 0.70 to indicate each item can be explained by the latent construct more than by error. The $t$-value of each loading should be twice the standard error of the loading. The item loadings, standard errors and their corresponding t-values are listed in Table 4. All but one item's loadings are greater than 0.70 . The results show that convergent validity is demonstrated.

Table 4. Measurement Item Statistics

\begin{tabular}{|l|l|l|l|l|l|}
\hline & & \multicolumn{1}{|c}{ Loadings } & \multicolumn{1}{c}{ Standard Error } & Critical Value & P Value \\
\hline & AR4 & 0.756 & 0.068 & 12.739 & $* * *$ \\
\hline & AR5 & 0.77 & 0.085 & 13.087 & $* * *$ \\
\hline & AR6 & 0.901 & 0.069 & 16.645 & $* * *$ \\
\hline & AR7 & 0.826 & 0.069 & 14.521 & $* * *$ \\
\hline Cognitive Risk & CR2 & 0.842 & 0.088 & 13.402 & $* * *$ \\
\hline & CR3 & 0.819 & 0.087 & 12.983 & $* * *$ \\
\hline Behavioral Intentions & PI1 & 0.761 & 0.063 & 9.311 & $* * *$ \\
\hline & PI2 & 0.805 & 0.066 & 9.619 & $* * *$ \\
\hline & PI4 & 0.586 & 0.062 & 7.548 & $* * *$ \\
\hline & PI6 & 0.7 & 0.056 & 8.754 & $* * *$ \\
\hline
\end{tabular}

The above analyses demonstrate the convergent validities and discriminant validities for the five constructs. Their final measurement items are listed in Table 5.

Table 5. Final Measurement Scale Items

\begin{tabular}{|l|l|}
\hline \multicolumn{1}{|c|}{ Constructs } & \multicolumn{1}{c|}{ Items } \\
\hline Affective Risk & I feel tense when I am going to purchase from the web store. \\
\hline & I am concerned about possible privacy violations from this web store. \\
\hline & I worry about my order if I purchase from this web store. \\
\hline & I feel uneasy about the quality of the health products offered by this store. \\
\hline & \\
\hline & This web store might ship me products that do not function properly. \\
\hline & I might receive wrong products from this store. \\
\hline & \\
\hline & I can rely on this web store to purchase to purchase my product. \\
\hline & I trust this web store completely. \\
\hline & I am very likely to provide the web store with my personal information. \\
\hline & I intend to purchase the product from this web store. \\
\hline
\end{tabular}

\section{Study II}

The purpose of Study II was to validate the instrument developed in study I by analyzing a separate sample data collected from a group of customers. Customers were recruited from an herb product store's online customer database. Each customer was given a $\$ 5$ coupon as an incentive to complete the survey. A total of 119 customers, 64 men and 55 women, completed at least some portions of the survey. Their average age was about 45 . These customers were veteran Internet users, with an average online experience of approximately seven years and an average of 20 online purchases per person. An email with an embedded link to the online questionnaire was sent to the store's customers to invite them to participate in the study. The customers were first asked about their demographic information and their general online shopping experience. They were then directed to the questionnaire to complete the survey. All the data entry was completed online. The instruments developed in Study I were modified to tailor to the herb store. A sample item is "I feel attached to (name of the online store)." 
Volume 19, Issue 3, pp. 11-21, 2018

\section{Results}

The instruments fit the data reasonably well with appropriate fit indices such as the discrepancy ratio (1.35), the adjusted goodness-of-fit (0.83), the comparative fit index (.98), Tucker-Lewis Index (0.97), the incremental fit index (0.98) and the root mean square error of approximation (0.054). The item loadings, standard errors and their corresponding t-values are listed in Table 6 . All but one item loadings are greater than 0.70 . The results show that convergent validity is demonstrated.

Table 6. Study 2: Measurement Item Statistics

\begin{tabular}{|l|l|l|l|l|l|}
\hline & & Loadings & \multicolumn{1}{|c|}{ Standard Error } & \multicolumn{1}{|c|}{ Critical Value } & \multicolumn{1}{c|}{ P Value } \\
\hline & AR4 & 0.878 & 0.072 & 11.991 & $* * *$ \\
\hline & AR5 & 0.844 & 0.092 & 11.256 & $* * *$ \\
\hline & AR6 & 0.956 & 0.057 & 13.868 & $* * *$ \\
\hline & AR7 & 0.861 & 0.064 & 11.625 & $* * *$ \\
\hline Cognitive Risk & CR1 & 0.88 & 0.099 & 10.421 & $* * *$ \\
\hline Behavioral Intentions & CR2 & 0.856 & 0.085 & 10.083 & $* * *$ \\
\hline & PI1 & 0.84 & 0.053 & 7.932 & $* * *$ \\
\hline & PI2 & 0.81 & 0.057 & 7.743 & $* * *$ \\
\hline & PI4 & 0.607 & 0.072 & 6.026 & $* * *$ \\
\hline & PI5 & 0.763 & 0.043 & 7.388 & $* * *$ \\
\hline
\end{tabular}

Average variance extracted (AVE) values for each construct were used to further demonstrate the convergent and discriminant validity. The convergent validity can be established if AVEs of each construct exceed the criteria (0.5) set by Fornell and Larcker (1981). Discriminant validity can be shown if the AVEs are greater than the cross correlations among constructs. As shown in Table 7, all constructs met the criteria suggested by Fornell and Larcker. Therefore, $\mathrm{H} 1$ is supported.

Table 7. Study 2: Correlations and AVEs from SEM Analysis

\begin{tabular}{|l|l|l|c|}
\hline & \multicolumn{1}{|c|}{ Affective risk } & Cognitive risk & BI \\
\hline Affective risk & $\mathbf{0 . 7 8}$ & & \\
\hline Cognitive risk & 0.54 & $\mathbf{0 . 7 5}$ & \\
\hline BI & -0.44 & -0.46 & $\mathbf{0 . 5 8}$ \\
\hline Composite reliability & $\mathbf{0 . 9 4}$ & $\mathbf{0 . 8 6}$ & $\mathbf{0 . 8 4}$ \\
\hline
\end{tabular}

The predictive validities of the constructs were assessed by associating the affective risk and cognitive risk with consumer behavioral intentions in a nomological network. The joint influence of affective risk and cognitive risk explained $28 \%$ of the variance of behavioral intentions. Cognitive risk has a strong influence on affective risk and can explain $30 \%$ of variance in affective risk alone. Therefore, $\mathrm{H} 2$ is supported. Affective risk is not only significant in the results but also has stronger influence on intentions than cognitive risk. H3 is also supported. The results are shown in figure 2. RMSEA is 0.086 which is just above the recommended guidelines (0.08) for a good fit (MacCallum, et al, 1996). Overall, the predictive validity for affective risk is supported. 


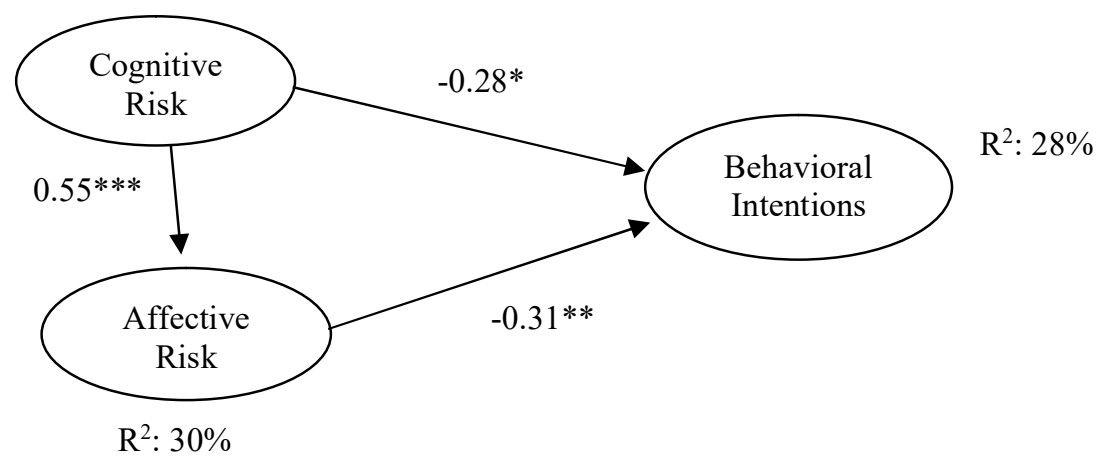

Figure 2. Testing Results for the Hypotheses

\section{DISCUSSIONS, IMPLICATIONS AND LIMITATIONS}

The measurement instruments developed for affective risk demonstrated appropriate internal consistency, convergent validity and discriminant validity. The scale for affective risk consists of items about customers' feelings of worry or fear about potential negative consequences if a purchase is made from the online vendor. This scale is the first scale to measure feelings of risk in an uncertain or risky environment, particularly in B2C ecommerce when customers need to transact with an unknown web vendor. Although previous scales such as DES II or DES III (Westbrook and Oliver, 1991), and fear arousal or worry (Richins, 1997) do measure customers' negative feelings, those items do not anchor in any particular aspect of a process. Therefore, it is not clear what the sources for the feelings of worry, dread or fear are. Most items for various computer anxiety scales only concern negative feelings about using computers in general (Compeau, Higgins, and Huff, 1999; Venkatesh 2000). The affective risk scale focuses on the potential negative feelings in $\mathrm{B} 2 \mathrm{C}$ ecommerce. The comparison between affective risk items and other computer anxiety items is listed in Table 8 . The newly developed affective risk scale specifically ties the negative feelings with customers' behavioral dispositions and the potential consequences upon the realization of these dispositions.

This study defined the construct of affective risk and identified its theoretical bases. This study also developed measurement scales for affective risk in B2C ecommerce context. The empirical results demonstrated their satisfactory psychometric properties. This study found that affective risk feelings indeed have unique and significant influence on behavioral intentions beyond its cognitive counterpart and could mediate the influence of design features on people's choices. Future research may examine the validity of the model and the mediation effect in other research contexts, such as employee and employer relationship or B2B ecommerce. This study did not examine the antecedents of affective risk. Therefore, future research may be directed at examining potential antecedents of affective risk besides the limited exploration in this study. This study is an application of the risk-asfeeling theory in $\mathrm{B} 2 \mathrm{C}$ ecommerce, and confirmed that affect, expressed as consumer feelings of worry, does play an important role in the consumer online shopping decision making process. Future research should address the role of emotions, particularly anticipatory emotions, on people's decision choices in other human-computer interaction contexts. This research shows that online vendors can influence consumers' behavioral intentions, such as purchase dispositions, willingness to depend on the vendor and willingness to provide private personal information, to reduce feelings of worry, fear or dread. Practitioners can use these results to guide their online business strategy. In the short term, web vendors should emphasize on risk reducing mechanisms to lower levels of affective risk feelings. Strategically, web vendors should attempt to build a long lasting, caring emotional bond with customers through revamped design strategies. 


\section{Issues in Information Systems \\ Volume 19, Issue 3, pp. 11-21, 2018}

Table 8. Comparison Between Affective Risk Scale and Other Scales

\begin{tabular}{|c|c|c|}
\hline Constructs & Items & Studies \\
\hline \multirow[t]{4}{*}{ Affective Risk } & I feel tense when I am going to purchase from the web store. & \multirow[t]{4}{*}{ New Scales } \\
\hline & $\begin{array}{l}\text { I am concerned about possible privacy violations from this web } \\
\text { store. }\end{array}$ & \\
\hline & I worry about my order if I purchase from this web store. & \\
\hline & $\begin{array}{l}\text { I feel uneasy about the quality of the health products offered by } \\
\text { this store. }\end{array}$ & \\
\hline \multirow[t]{2}{*}{ Negative Emotions } & $\begin{array}{l}\text { Fear arousal: scared; afraid, panicky, threatened, frightened, } \\
\text { alarmed }\end{array}$ & \multirow[t]{2}{*}{ Richins, 1997} \\
\hline & Worry: nervous, worried, tense, concerned, uneasy & \\
\hline \multirow[t]{4}{*}{ DES II } & $\begin{array}{l}\text { Below is a list of words that you can use to show how you feel. } \\
\text { We want you to tell us how strongly you feel. You can tell us } \\
\text { how strongly you feel each of these feelings on the list by } \\
\text { marking one of the numbers next to each question. }\end{array}$ & \multirow[t]{4}{*}{$\begin{array}{l}\text { Westbrook and } \\
\text { Oliver, 1991, } \\
\text { DES II }\end{array}$} \\
\hline & feel scared, uneasy, like something might harm you. & \\
\hline & feel fearful, like you're in danger, very tense. & \\
\hline & feel afraid & \\
\hline \multirow[t]{4}{*}{ Anxiety } & $\begin{array}{l}\text { It scares me to think that I could cause the computer to destroy a } \\
\text { large amount of information by hitting the wrong key. }\end{array}$ & \multirow{4}{*}{$\begin{array}{l}\text { Compeau, } \\
\text { Higgins, and } \\
\text { Huff, } 1999\end{array}$} \\
\hline & I feel apprehensive about using computers. & \\
\hline & $\begin{array}{l}\text { I hesitate to use a computer for fear of making mistakes I cannot } \\
\text { correct. }\end{array}$ & \\
\hline & Computers are somewhat intimidating to me. & \\
\hline \multirow[t]{9}{*}{ Computer Anxiety } & Computers do not scare me at all. & \multirow[t]{9}{*}{ Venkatesh 2000} \\
\hline & Working with a computer makes me nervous. & \\
\hline & I do not feel threatened when others talk about computers. & \\
\hline & It wouldn't bother me to take computer courses. & \\
\hline & Computers make me feel uncomfortable. & \\
\hline & I feel at ease in a computer class. & \\
\hline & I get a sinking feeling when I think of trying to use a computer. & \\
\hline & I feel comfortable working with a computer. & \\
\hline & Computers make me feel uneasy. & \\
\hline \multirow[t]{5}{*}{ Computer Anxiety } & Computers are a real threat to privacy in this country. & \multirow{5}{*}{$\begin{array}{l}\text { Stewart and } \\
\text { Segars, } 2002\end{array}$} \\
\hline & $\begin{array}{l}\text { Sometimes I am afraid the data processing department will lose } \\
\text { my data. }\end{array}$ & \\
\hline & $\begin{array}{l}\text { I am anxious and concerned about the pace of automation in the } \\
\text { world. }\end{array}$ & \\
\hline & I am easily frustrated by computerized bills. & \\
\hline & $\begin{array}{l}\text { I am sometimes frustrated by increasing automation in my } \\
\text { home. }\end{array}$ & \\
\hline
\end{tabular}

\section{LIMITATIONS AND CONCLUSIONS}

The first limitation is that undergraduate students were used in the processes of instrument development and experiment validation. Although IS researchers have presented arguments about the appropriateness of using students as subjects, especially in B2C ecommerce environments, this still presented a challenge to the external validity of the instruments and the research model. Data were collected from external customers to mitigate this threat and demonstrated that the findings from the student samples can be extended to the real customer sample. However, there is a possibility that the supporting evidence from the real customer sample might be an artifact embedded in the data. Therefore, it is necessary to test the model and instruments using customers from other sectors of the industry. Second, the external validity of the instruments and the research model was examined by 
analyzing data collected from customers of a hybrid online herb store. The physical existence of the store might have contributed to the weaker affective risk feelings. The experiment provided evidence for validity of the instruments and the research model regarding shopping from a pure online store. However, it would be beneficial if additional data from a "real" pure online store can support the findings of this study. Third, other important constructs might be omitted from the research model, such as trust propensity or risk propensity. A closer examination of the moderating influence of these constructs could provide a richer understanding of the impact affective risk on trusting intentions.

This paper examined the nature of affective risk and its construct validities in $\mathrm{B} 2 \mathrm{C}$ ecommerce environment. Drawing on the risk-as-feeling theory, this research provided the definitions for affective risk and developed measurement items for the construct. Data were collected through two field studies, and the findings supported the conceptualization of affective risk and its convergent and discriminant validities. The results also found that affective risk is a significant determinant of behavioral intentions. The findings from this research provide another step toward further our understanding of the nature and mechanisms of consumers' experience of risk in $\mathrm{B} 2 \mathrm{C}$ ecommerce environment. Practitioners can benefit from this study in terms of shifting their attention from solely focusing on reducing risk perception to attempting to build long lasting relationships with customers and to reduce their dreaded feelings from purchase from an online vendor.

\section{REFERENCES}

Bagozzi, R. P., Gopinath, M. \& Nyer, P. U. (1999). The role of emotions in Marketing. Journal of the Academy of Marketing Science, 27(2), 184-206.

Bargh, J. A. (1984). Automatic \& conscious processing of social information. In R. S. Wyer \& T. K. Srull (Eds.), Handbook of social cognition (Vol. 3, pp. 1-43). Hillsdale, NJ: Erlbaum.

Bhattacherjee, A. (2002). Individual trust in online firms: scale development \& initial test. Journal of Management Information Systems, 19(1), 211-241.

Clark, L. A. \& Watson, D. (1995). Constructing validity: basis issues in objective scale development. Psychological Assessment, 7, 309-319.

Compeau, D., Higgins, C. A. \& Huff, S. (1999). Social cognitive theory and individual reactions to computing technology: A longitudinal study. MIS Quarterly, 23, 145-158.

Crites, S. L., Fabrigar, L. R. \& Petty, R. E. (1994). Measuring the affective \& cognitive properties of attitudes: conceptual \& methodological issues. Personality \& Social Psychology Bulletin, 20, 619-634.

Featherman, M. S. \& Pavlou, P. A. (2003). Predicting e-services adoption: a perceived risk facets perspective. International Journal of Human-Computer Studies, 59, 451-474.

Fornell, C. \& Larcker, D. F. (1981). Evaluating structural equation models with unobservable variables and measurement error. Journal of Marketing Research, 18, 39-50.

Fortes, N. \& Rita, P. (2016). Privacy concerns and online purchasing behavior: towards an integrated model, European Research on Management and Business Economics, 22(3), 167-176.

Gefen, D., Karahanna, E. \& Straub, D. W. (2003). Trust and TAM in online shopping: An integrated model. MIS Quarterly, 27(1), 51-90.

Jarvenpaa, S. L., Tractinsky, N., \& Vitale, M. (2000). Consumer trust in an internet store. Information Technology \& Management, 1, 45-71. 


\section{Issues in Information Systems}

Volume 19, Issue 3, pp. 11-21, 2018

Loewenstein, G. F., Weber, E. U., Hsee, C. K. \& Welch, N. (2001). Risk as feelings. Psychological Bulletin, 127(2), 267-286.

McKnight, D. H., Choudhury, V. \& Kacmar, C. (2002a). Developing \& validating trust measures for e-Commerce: an integrative typology. Information Systems Research, 13, 334-359.

McKnight, D. H., Choudhury, V. \& Kacmar, C. (2002b). The impact of initial consumer trust on intentions to transact with a web site: a trust building model. Journal of Strategic Information Systems, 11, 297-323.

MacCallum, R. C., Browne, M. W., \& Sugawara, H. M. (1996). Power Analysis and Determination of Sample Size for Covariance Structure Modeling. Psychological Methods, 1(2), 130-149.

Murphy, S. T. \& Zajonc, R. B. (1993). Affect, cognition, and awareness: affective priming with optimal and suboptimal stimulus exposures. Journal of Personality and Social Psychology, 64, 723-739.

Panksepp, J. (1985). Mood changes. In P. J. Vinken, G. W. Buyn, \& H. L. Klawans (Eds.), Handbook of clinical neurology. Revised series: Vol. 1. Clinical neuropsychology (pp. 271-855). Amsterdam: Elsevier Science.

Panksepp, J. (1998). Affective neuroscience. New York: Oxford University Press.

Richins, M. L. (1997). Measuring emotions in the consumption experience. Journal of Consumer Research, 24, $127-$ 146.

Servan-Schreiber, D. \& Perlstein, W. M. (1998). Selective limbic activation and its relevance to emotional disorders. Cognition \& Emotion, 12, 331-352.

Torkzadeh, G. \& Dhillon, G. (2002). Measuring factors that influence the success of Internet commerce. Information Systems Research, 13, 187-204.

Yang, S., Chen, Y., Wei, J. (2015). Understanding consumers' web-mobile shopping extension behavior: a trust transfer perspective. Journal of Computer Information Systems, 55(2), 78-87.

Yen, Y. (2015). Managing perceived risk for customer retention in e-commerce: the role of switching costs. Information and Computer Security, 23(2), 145-160.

Zajonc, R. B. (1980). Feeling \& thinking: Preferences need no inference. American Psychologist, 35, 151-175. 